\title{
Traditional Versus Authentic Assessments in Higher Education
}

\author{
Al-Sabbah Saher ${ }^{\mathrm{a}}$; Al Momani Jehad Ali ${ }^{\text {b*; }}$ Darwish Amanic; and Fares Najwan ${ }^{\text {d }}$ \\ aDepartment of Psychology, Fatima College of Health Sciences, Abu Dhabi City, UAE \\ ${ }^{\text {b}}$ Department of Curricula and Teaching Methods, College of Educational and Psychological Sciences, Amman Arab University, Amman \\ city, Jordan, \\ 'Department of General Requirements/ Special and Inclusive Education, Fatima College of Health Sciences, Abu Dhabi City, UAE, \\ dDepartment of General Requirements/ Science Education, Fatima College of Health Sciences, Abu Dhabi City, UAE, ORCHID ID: https:// \\ orcid.org/0000-0002-9796-5233,Email: najwan.fares@fchs.ac.ae
}

\begin{abstract}
This study aimed to explore the effect of authentic and traditional assessment on students' performance in the field of health and educational sciences. Both qualitative and quantitative research designs were used in this study. Study used A questionnaire containing 20 items: 10 items represented traditional assessment and the other 10 represented authentic assessments has been used in this study. The survey sample used in this study consisted of 157 students and 52 educators. In addition, 10 educators were interviewed for the qualitative research part and 25 graduate students as an experimental sample. The main findings of this study indicated that educators preferred using both traditional testing tools and the preference towards traditional and authentic tools depended on academic qualification. This implies the importance of conducting institution in-service courses for educators, which may depend not only on the nature of the training but also on the academic qualifications of the participants. Furthermore, it is important to note that while many educators reported their preference in utilizing novel evaluation methods, a small proportion of them did not deem authentic assessment as their preferred way of assessing students' performance. This could partly be the result of adopting a traditional curriculum instead. various outcomes of this study can lead educators to design a best model of assessment using both traditional and authentic assessment types. As for students, many advantages of using authentic assessment will help them enhance their academic writing and productivity skills.
\end{abstract}

Keywords: Authentic Assessment; Accreditation; Students' Performance Traditional Assessment.

\section{INTRODUCTION}

Assessment is one of the essential components of teaching and instruction that influences the many stakeholders and partnerships in the educational community, such as instructors, parents, guardians, students, policymakers, and administrators (Dietel, Herman, and Knuth 1991). Assessment is defined as any form of measurement and evaluation of what students know and can do (Brawley 2009). Assessment plays an integral role in identifying the level of effectiveness of a certain process and the result of the learning itself. However, the outcome of learning is largely dependent on the effectiveness and accuracy of the assessment developed (Karim, Darman and Mohammad, 2018). There are two main subgroups used when describing assessments: traditional and authentic.

Traditional assessments, as stated by Bailey (1998), are indirect and inauthentic types of testing that are one-shot, speed-based, and norm-referenced. These assessments measure what learners can do at a specific time. However, test scores cannot tell anything about the students' progression. Similarly, they cannot tell what difficulties the student had during the test (Dikli, 2003). Traditional or conventional assessment is limited to standardized paper-and-pencil/pen tests, which emphasize objective measurement (Koh, 2017). These standardized assessments employ closed-ended item formats, such as multiple choice, matching, essays, short-answer questions, or true/false. The use of these item formats is thought to increase the efficiency of test administration, scoring objectivity, test score reliability, and cost effectiveness as machines are used for scoring; thus, large-scale administration of test items is possible. However, it is widely recognized that traditional testing limits the assessment of higher-order thinking skills and other essential 21st-century competencies due to the nature of the item format (Koh 2017). Bailey (1999) also mentions that there is no feedback provided to students in this type of assessment. Similarly, Simonson et al. (2000) state that traditional or conventional assessments focus on learners' ability to memorize and recall, which are in the lower level of Bloom's Taxonomy. From a psychometric perspective, rigorous and higher-level learning outcomes, such as critical thinking

Corresponding Author e-mail: Jmomani@aau.edu.jo

https://orcid.org/0000-0002-3243-4351

How to cite this article: AL.sabbah,S. Almomani,J. Drawish, A\& Fares,N. (2022). Traditional versus authentic assessments in higher education. Pegem Journal of Education and Instruction, 12(1), 283-291.

Source of support: Nil

Conflict of interest: None.

DOI: $10.47750 /$ pegegog.12.01.29

Received: 11.10 .2021

Accepted: 18.12.2021 Publication: 01.01.2022 
and problem solving, are too subjective to be tested while using the traditional assessment. Nevertheless, conventional assessments motivate students to study, make them aware of what they have learned and where they need to study more. Thus, it can act as a tool for learning, contributing to the process and outcomes of learning (Weurlander et. al 2012).

However, authentic assessment refers to a process that is based on reflection on the teaching, learning, achievement, motivation, and attitudes of both teachers and students during the teaching and learning process (Karim et. al 2018). These tests are used to determine if students can apply the knowledge they have acquired in a real-world setting (Frey and Schmitt 2007). This type of assessment examines students' performance on intellectual tasks (Brawley 2009). Some authentic assessment tools used are portfolios, projects, and journals. They allow students to express their knowledge on the material in their own way. The results obtained from these tests can be used to assist and guide students in their development and learning processes (McAfee and Leong 2007). Authentic assessment is considered an effective measure of intellectual achievement or ability because it requires students to demonstrate their deep understanding, higher-order thinking, and complex problem solving through the performance of archetypal tasks. Hence, authentic assessment can serve as a powerful tool for assessing students' 21 st-century competencies in the context of global educational reforms, such as providing them with opportunities to practice the real-life activities that they might be assessed by authentic assessment. Such activities might allow them to transfer their knowledge and skills to numerous realworld scenarios. Moreover, collaborative work is encouraged (Koh 2017). The main findings of the study by Moria, Refnaldi, and Zaim (2017) showed that authentic assessment could be a useful tool to encourage students' motivation in essay writing using their critical thinking potentials. Moreover, the results indicated that the observed students in the study were excited to finish their assigned assignments on time. Thus, authentic assessment helps educators to assess students' skills in writing. Based on research findings by Wylie, E. C., \& Lyon, C. J. (2020) it was proven that students' perceptions about assessment significantly influence their learning and studying approaches. Students' study methodologies affect their perceptions of evaluation and assessment. In this favor, students prefer multiple-choice question exams to short essay type questions, which are typical traditional assessment tools. However, when compared to the authentic assessment methods, students prefer using these innovative assessment methods as they are fairly evaluated.

As a final conclusion in his study, Winking (1997) indicated that alternative assessments assisted educators to have a better understanding of their students' learning by looking at their products rather than scores, which allowed educators to gain advance insights regarding students' knowledge, performance, and skills. There has been a movement from traditional to alternative assessments.

In previous studies related to selecting an accurate and veracious method for assessing learners, Quansah (2018) indicated that to determine the best type of assessment, educators needed to consider some criteria based on the advantages and disadvantages of each assessment type. The purpose of the assessment should be paramount in deciding which type to use while evaluating students' skills and knowledge, and the main criteria for the decision are basically based on the nature of the material.

There has been a major change in the way traditional assessment is being viewed as the only method of assessment by looking further for alternative assessments that could be used as a resource for educational reform due to the increasing concern and awareness of the influence of testing on instruction and curriculum (Dietel, Herman, and Knuth 1991).

\section{Method}

This study aimed to understand the effectiveness of using authentic and traditional assessments on students' performance in the field of health and educational sciences. This experimental research used both quantitative and qualitative research methods. This type of research is expected to help teachers and educators determine the appropriate method of assessment that influences their students' performance and academic achievement. The method used in this study was focused on an experimental trial to compare one group of students enrolled in two introductory psychology courses with almost the same level of difficulty and content similarity. The selected courses used two types of assessments: traditional and authentic. The selected students were the same students in both courses. The final grades were compared in both courses.

In addition, the study used a questionnaire to obtain the students and instructors' preferences and attitudes towards both types of assessments. Moreover, the qualitative data were obtained by interviewing several educators.

\section{Research Questions}

This study attempts to answer the following questions:

- What are the attitudes and perceptions of learners and educators regarding the use of authentic and traditional assessment strategies?

- What are the advantages and disadvantages of using authentic assessment in evaluating learners in higher education?

- What are the advantages and disadvantages of using traditional assessment in evaluating learners in higher education?

- To what extent does the assessment type influence students' academic performance in higher education? 
- Is there any significant difference between participants' perceptions and attitudes in terms of gender and levels of qualifications towards using authentic and traditional assessments?

\section{Population and Sample}

The study population consisted of academic staff and undergraduate students from FCHS and postgraduate students from Amman Arab university. A random sampling strategy was used to determine the participants in this study. The selected sample consisted of 157 undergraduate students and 52 educators. In addition, a sample of one postgraduate class that consisted of 25 students from Amman Arab University in Jordan was selected as an experimental sample to compute the difference between students' academic performance using the two assessment tools: authentic assessment using an assignment and traditional assessment using an examination.

\section{Data Collection}

A questionnaire consists of 20 items in two different formats has been used in this study, one for educators and another one for students, to obtain their preferences and attitudes towards authentic and traditional assessments. Furthermore, the researchers interviewed 10 academic staff from Fatima College of Health Sciences (FCHS), a public university in the Emirate of Abu Dhabi, United Arab Emirates and from Amman Arab University in Jordan.

The questionnaire was validated using the face and content validity method by sending the questionnaire items to 10 experts in the field of education and psychology from FCHS and Amman Arab University. The experts' evaluation and validation were conducted to obtain experts' feedback and suggestions. The questionnaire items were modified, removed, or replaced. Assessment and constructive feedback were provided by the experts in the form of valuation suggestions using validation sheets. Based on that, a number of 11 items were removed from the initial draft of the questionnaire and 4 items were modified based on the experts' suggestions and recommendations, and the final number of items in the finalized questionnaire was 20 .

In addition to that, the reliability coefficient for the questionnaire was computed using Cronbach's Alpha analysis model to determine the internal consistency of the whole scale and for each type of assessment. The values of the Cronbach's Alpha were found to be 0.71 for the whole questionnaire, 0.73 for the traditional assessment part and 0.58 for authentic assessment part.

The data analysis method used in this study was based on descriptive analysis to measure the students and educators' preferences and attitudes towards both types of assessments. That is, a comparison was used to determine the average between students' final grades in both courses. One-way ANOVA was used to determine if there was any significant difference between male and female educators when using the two types of assessments.

\section{Results}

The results of the quantitative data represented in this section:

The mean and standard deviation were found for each item in the questionnaire that represents the students' responses.

The results which state that the highest items in the authentic assessment were item 13 (I prefer tasks that are challenging and that have more than one answer) with a mean value of 4.58 and standard deviation of 0.69 and item 17 (I prefer questions that require the application of material learned to new situations) with a mean value of 4.25 and standard deviation of .74. Furthermore, the results indicated that the highest items in the traditional assessment were item 10 (I prefer computerized tests) with a mean value of 4.44 and standard deviation of 0.61 , and item 9 (I prefer simple tasks that have only one correct answer) with a mean value of 4.23 and .81 for standard deviation.

However, the results indicated that the lowest items in the authentic assessment were item 19 (I prefer questions that

Table 1: The descriptive statistics for students' responses for each item

\begin{tabular}{|c|c|c|c|c|c|c|}
\hline Item No & Assessment Type & Item Description & $N$ & Sum & Mean & Std. Deviation \\
\hline Q13 & Authentic & $\begin{array}{l}\text { I prefer tasks that are challenging and have more } \\
\text { than one answer. }\end{array}$ & 157 & 719 & 4.58 & 0.69 \\
\hline Q10 & Traditional & I prefer computerized tests. & 157 & 691 & 4.4 & 0.619 \\
\hline Q17 & Authentic & $\begin{array}{l}\text { I prefer questions that require the application of } \\
\text { material learned to new situations. }\end{array}$ & 157 & 667 & 4.25 & 0.74 \\
\hline Q9 & Traditional & I prefer simple tasks that have only one correct answer. & 157 & 664 & 4.23 & 0.808 \\
\hline Q2 & Traditional & I prefer written tests, without supporting materials. & 157 & 532 & 3.39 & 0.952 \\
\hline Q1 & Traditional & $\begin{array}{l}\text { I prefer written tests, with supporting materials } \\
\text { (notes, books). }\end{array}$ & 157 & 523 & 3.33 & 1.094 \\
\hline Q19 & Authentic & I prefer questions that require scientific investigation. & 157 & 505 & 3.22 & 1.151 \\
\hline Q12 & Authentic & $\begin{array}{l}\text { I prefer tasks that require personal opinions or } \\
\text { explanation. }\end{array}$ & 157 & 464 & 2.96 & 1.346 \\
\hline
\end{tabular}


require scientific investigation) with a mean value of 3.22 and standard deviation of 1.15 and item 12 (I prefer tasks that require personal opinions or explanation) with a mean value of 2.96 and standard deviation of 1.35 . In addition, the results indicated that the lowest items in the traditional assessment were item 1 (I prefer written tests, with supporting materials (notes, books) with a mean value of 3.33 and standard deviation of 1.1 and item 2 (I prefer written tests, without supporting materials) with a mean value of 3.39 and .952 for standard deviation.

The overall results for the mean comparison using t-test for both types of assessment indicated that there was a significant difference between students' responses to both types of assessment (authentic and traditional) with a p-value of 0.05 . The mean values of traditional and authentic assessments were 3.78 and 3.84, respectively. Both values were significant at a $\mathrm{p}$-value of 0.05 , as shown in the above table.

The results indicated that there were no statistically significant differences between year of study compared to the two types of assessments using one-way ANOVA analysis, as shown in Table 3. As for traditional assessment, the significance value was found to be .103, which was higher than the significance level of p-value (0.05) used in this analysis. For authentic assessment, the significance value was found to be .912 , which was higher than the significance level of $\mathrm{p}$-value (0.05) used in this analysis.

Table 4 shows that there are seven items (item 20, 18, 17, 19, 15,11 , and 16) from authentic assessment that have the highest means in comparison to other items in the questionnaire. The range of value is (4.4 to 4.19 ), which means that most of the educators' responses were 4 and 5 in the scale.

The results in Table 5 show that there is a significant difference between the means of authentic and traditional assessment at a significance level of 0.05 . The mean values of authentic and traditional assessments are 4.14 and 3.39, respectively. These results indicate that most of the educators preferred using authentic assessment more than traditional assessment to evaluate their students' performance.

The output of Two-Way ANOVA analysis in Table 6 indicates that there is no statistically significant difference between male and female educators in determining their preferences for using traditional assessment for evaluating their students' performance at a significance level of 0.05 .

Figure 1 shows that the responses of male educators with a PhD degree were slightly less than that of the female educators with a $\mathrm{PhD}$ degree in preference to using traditional assessment as a tool to assess students, while both female and male educators with a Master's degree showed more preference for using traditional assessment as a tool to assess students' performance.

The output of Two-Way ANOVA analysis in Table 6 indicates that there is no statistically significant difference between male and female educators in determining their preferences for using authentic assessment to evaluate their students' performance at a significance level of 0.05 .

Figure 2 shows that the responses of male educators with a PhD degree were slightly less than that of the female educators with a PhD degree in preference to authentic assessment as a tool to assess students, while both female and male educators holding a Master's degree showed more preference towards using authentic assessment as a tool to assess students' performance.

The results in Table 7 show that there is a statistically significant difference between students' grades in both types of assessments, traditional and authentic, where the students achieved higher grades in their exam in comparison to their grades in the assignment. The mean of student grades in the exam was 25.55 , while the mean of the student grades in the

Table 2: Overall descriptive statistics for both types of assessment using one sample t-test for students' responses

\begin{tabular}{llllll}
\hline Assessment Type & $N$ & Mean & Std. Deviation & $t$ & Sig. (2-tailed) \\
\hline Traditional & 157 & 3.7796 & .46914 & 100.94 & .000 \\
Authentic & 157 & 3.8389 & .45031 & 106.81 & .000 \\
Valid N (list wise) & 157 & & & & \\
\hline
\end{tabular}

Table 3: Descriptive statistics and one-way ANOVA for a year of study and type of assessment

One-Way ANOVA

\begin{tabular}{|c|c|c|c|c|c|}
\hline Average for Tradition & Sum of Squares & $D f$ & Mean Square & $\mathbf{F}$ & Sig. \\
\hline Between Groups & 1.356 & 3 & .452 & 2.097 & .103 \\
\hline Within Groups & 32.979 & 153 & .216 & & \\
\hline Total & 34.335 & 156 & & & \\
\hline Average for Authentic & Sum of Squares & $D f$ & Mean Square & $F$ & Sig. \\
\hline Between Groups & .109 & 3 & .036 & .177 & .912 \\
\hline Within Groups & 31.524 & 153 & .206 & & \\
\hline Total & 31.633 & 156 & & & \\
\hline
\end{tabular}


Table 4: Descriptive statistics for staff responses for each item

\begin{tabular}{|c|c|c|c|c|c|c|}
\hline Item No & Assessment Type & Item Description & $N$ & Sum & Mean & Std. Deviation \\
\hline Q20 & Authentic & $\begin{array}{l}\text { I prefer giving students questions that require problem } \\
\text { solving. }\end{array}$ & 52 & 231 & 4.44 & 0.777 \\
\hline Q18 & Authentic & $\begin{array}{l}\text { I prefer giving students questions that require critical } \\
\text { thinking. }\end{array}$ & 52 & 229 & 4.40 & 0.603 \\
\hline Q17 & Authentic & $\begin{array}{l}\text { I prefer giving students questions that require the } \\
\text { application of material learned to new situations. }\end{array}$ & 52 & 223 & 4.29 & 0.536 \\
\hline Q19 & Authentic & $\begin{array}{l}\text { I prefer giving students questions that require } \\
\text { scientific investigation. }\end{array}$ & 52 & 219 & 4.21 & 0.667 \\
\hline Q15 & Authentic & $\begin{array}{l}\text { I prefer giving students tasks that require creativity } \\
\text { and imagination. }\end{array}$ & 52 & 219 & 4.21 & 0.750 \\
\hline Q11 & Authentic & $\begin{array}{l}\text { I prefer giving students tasks related to real life } \\
\text { situations. }\end{array}$ & 52 & 218 & 4.19 & 0.841 \\
\hline Q16 & Authentic & $\begin{array}{l}\text { I prefer giving students tasks to help them become } \\
\text { reflective learners (portfolios and self-refection). }\end{array}$ & 52 & 218 & 4.19 & 0.864 \\
\hline Q7 & Traditional & $\begin{array}{l}\text { I prefer giving students concept maps (charts } \\
\text { expressing relationship between concepts). }\end{array}$ & 52 & 202 & 3.88 & 0.704 \\
\hline
\end{tabular}

Table 5: Overall descriptive statistics for both types of assessment with t-test comparison for staff responses

\begin{tabular}{llllll}
\hline & $N$ & Mean & Std. Deviation & $T$ & Sig. \\
\hline Traditional & 52 & 3.3942 & .40459 & 60.49 & .000 \\
Authentic & 52 & 4.1442 & .54680 & 54.65 & .000 \\
Valid N (list wise) & 52 & & & & \\
\hline
\end{tabular}

Table 6: Two-Way ANOVA analysis for educators' preferences towards traditional assessment for two independent variables: gender and qualifications

\begin{tabular}{llllll}
\hline Traditional Assessment & Type III Sum of Squares & Df & Mean Square & $F$ & Sig. \\
\hline Corrected Model & $.844 \mathrm{a}$ & 4 & .211 & 1.321 & .276 \\
Intercept & 259.704 & 1 & 259.704 & 1626.463 & .000 \\
Gender & .031 & 1 & .031 & .192 & .663 \\
Qualifications & .745 & 2 & .372 & .332 & .108 \\
Gender ${ }^{*}$ Qualifications & .112 & 1 & .112 & .705 & .406 \\
Error & 7.505 & 47 & & & \\
Total & 607.430 & 52 & & & \\
Corrected Total & 8.348 & 51 & & & \\
\hline
\end{tabular}

a. R Squared $=.101($ Adjusted R Squared $=.025)$

assignment was 22.60. By comparing these two means using the One-Sample t-test as shown in Table 8, the results indicated significant differences between both grades at a level of 0.05 .

\section{Discussion}

The data analysis in this study helped map out patterns between perceptions of students and educators in higher education regarding assessment practices. The results of this study illustrate that institutions in higher education are taking important steps towards educational reform and are now adopting diverse evaluation approaches when assessing their students, and these varied ways range along a continuum between traditional and authentic assessments.

Educators who preferred the adoption of authentic assessment may have been positively influenced by the findings of the recent research that aimed to improve the assessment practices in higher education. Wylie, E. C., \& Lyon, C. J. (2020) mentioned that innovative assessment practices have the potential to change the way universities operate by rethinking assessment design to enable students to work collegially and to be engaged in the assessment process such self and peer assessment. In light of the UAE national policy 2030 that focuses on the role of higher education 


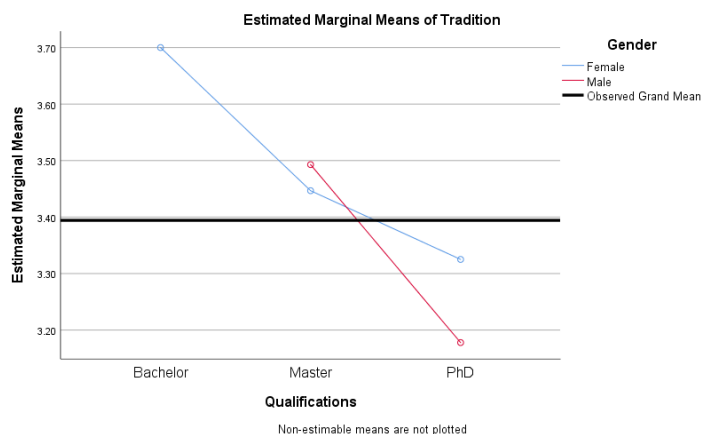

Fig. 1: The distribution of male and female educators with relevance to their qualifications.

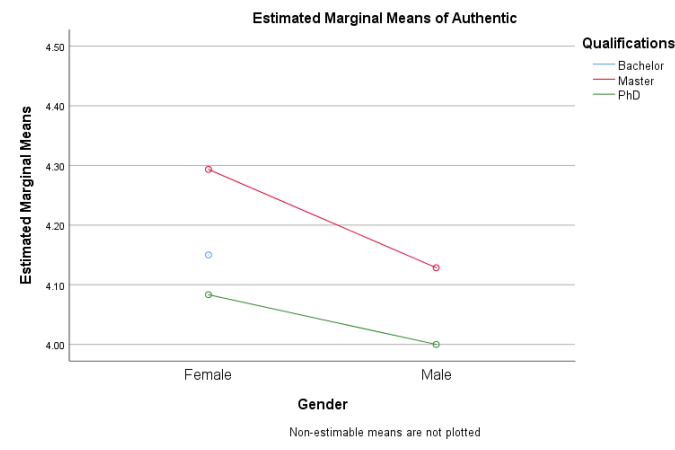

Fig. 2: The distribution of male and female educators with relevance to their qualifications.

Table 7: Two-Way ANOVA analysis for educators' preferences for authentic assessment for two independent variables: gender and qualifications

\begin{tabular}{|c|c|c|c|c|c|}
\hline Authentic Assessment & Type III Sum of Squares & $D f$ & Mean Square & $F$ & Sig. \\
\hline Corrected Model & $.569^{\mathrm{a}}$ & 4 & .142 & .455 & .768 \\
\hline Intercept & 372.082 & 1 & 372.082 & 1191.306 & .000 \\
\hline Gender & .185 & 1 & .185 & .593 & .445 \\
\hline Qualifications & .349 & 2 & .174 & .558 & .576 \\
\hline Gender ${ }^{\star}$ Qualifications & .020 & 1 & .020 & .064 & .802 \\
\hline Error & 14.680 & 47 & .312 & & \\
\hline Total & 908.330 & 52 & & & \\
\hline Corrected Total & 15.248 & 51 & & & \\
\hline
\end{tabular}

a. R Squared $=.037$ (Adjusted R Squared $=-.045$ )

institutions in catalyzing the growth of the UAE economy, the UAE government launched the National Strategy for Higher Education 2030, which intends to place higher education in the UAE among the world's top institutions. Considering this hard dimension, which includes assertions and government policies, the soft aspect infiltrates institutions in higher education where educators are requested to improve their quality of teaching to help students of different abilities acquire 21st century skills. This is consistent with the Universal Design for Learning (UDL), which is an approach that calls for giving all learners equal opportunity to learn and succeed and encourages flexibility in the way learners access content, interact with it, and show their understanding of what they learned (Meyer and Rose 2000).

According to the results of this study, many educators preferred using both traditional testing tools that were created to determine the number of correct responses scored by a student and authentic testing tools that were constructed based on the evaluation of student processes, skills, and competencies. This divergence in attitudes of educators towards traditional and authentic assessments reflects the dissatisfaction of some educators in higher education with the limitations of traditional testing techniques and echoes the continued confidence in the value of multifaceted assessment, which asks students to perform, create, produce, or do something that requires them to use higher-level problem-solving skills.
These tasks represent meaningful instructional activities, which are also relevant to students' real-life. Therefore, this study demonstrated that educators in higher education tend to adopt novel methods to evaluate students' academic performance and assess their understanding of the skills acquired and information taught. This finding corresponded with the findings of Wright, Knight, and Pomerleau (1999) that stated that many educators are now adopting innovative teaching methods in higher education that can be utilized to enhance student engagement and learning help in developing learners' leadership identity and competencies (Wiewiora \& Kowalkiewicz 2019; Wilsey, M, et al. 2020).

Although this change in the way students are being evaluated does not seem to be occurring at a large scale, it can be considered a positive step towards using more effective tools to measure students' understanding. It is also evident that several educators prefer using portfolios in the classroom, which is one example of the beginning of significant changes to student evaluative practices in higher education. This preference can be associated with the inclination of many educators to assess students' creativity and innovation that can be captured by portfolio creations. Moreover, the data show that the use of a new variety of evaluating tools is also based on an awareness that teaching students how to be reflective learners is a very important skill for future health care providers as reflection enhances 
personal development, leading to improvement in patient care through expanding and developing clinical knowledge and skills. Furthermore, the limitations of traditional assessment practices appear to have amplified the interest of educators towards authentic assessment methods. Many educators in this study were in favor of authentic assessment methods, which can be attributed to their success in using it in the past or because they anticipated that their students would benefit from them. Moreover, the results of this study also revealed the flexibility of educators and their eagerness to try new ideas and different forms of assessment that can help enhance the academic achievement of students. An important factor that plays an imperative role in the academic success of students is their motivation to learn and continue their academic journey until they graduate. Moria, Refnaldi, and Zaim (2017) reported that authentic assessment could be a useful tool to encourage students' motivation in writing essay using their critical thinking potentials. It seems clear that training and professional development provided in college in the past three years include examples and practices with varied and diverse evaluation methods, which many educators find beneficial to adapt to enhance their teaching practices in higher education.

The results also indicated Displayed a difference in educators' preference towards traditional and authentic assessments can be dependent on academic qualification. Educators who had higher academic qualifications showed more preference to try out authentic assessment than those who had lower academic qualifications. This implies the importance of organizing institution in-service courses for educators, which may depend not only on the nature of the training but also on the academic qualifications of the participating educators. It is also important to note that while many educators reported their preference in utilizing novel evaluation methods, a small proportion of educators did not deem the authentic assessment as their preferred way of assessing students' performance. This could partly be the result of adopting a traditional curriculum.

The results of the semi-structured interview with ten educators showed that educators generally perceived that traditional and authentic assessment practices had advantages and disadvantages. When asked about the advantages of traditional assessment, some educators reported that it was a quick and reliable tool to assess a wide range of concepts. Most educators believe that this type of assessment is practical because it can be easily constructed and answers can be easily corrected based on a defined answer key, leaving no room for subjective evaluation of the answers, which makes it a reliable tool for assessing students' understanding of some selected concepts. These findings were confirmed by Dikli (2003) and DeLuca, et al. (2016) who reported that traditional assessments, such as multiple-choice tests, were fast, easy, reliable, and objective to evaluate students' understanding of particular concepts. It can be assumed that educators usually favor such types of assessments as they can maintain fairness in assessment, which enhances trustful relationships between educators and students. However, educators have identified different downsides to traditional assessments, such as promoting rote memorization, and its limitations in measuring personal skills, multiple abilities, and deep thinking processes of students. Moreover, it maximizes students' stress, can create anxieties, and heighten test apprehension. These findings corresponded to the disadvantages pointed out by Law and Eckes (2007) who mentioned that traditional assessment assesses lower order thinking skills of learners and focuses on assessing the ability of learners to memorize and recall, which are lower levels of cognitive skills.

Regarding the advantages and disadvantages of authentic assessment, most educators reported that the advantages of authentic assessment included its ability to test students' deep understanding of different concepts. Furthermore, it measures higher-order thinking abilities of students and enables them to be ready for real-life scenarios and experiences to solve problems that are vital for health science students where they need to analyze different health-related scenarios and should be able to provide proper and sound interventions to patients. These findings match those of Ghosh et al. (2020) that authentic assessment methods require students to use critical thinking and analytical thoughts to construct responses of information presented in real-world scenarios that could enable students to be guided towards significantly higher academic achievement. Furthermore, Mattison et al. (2020) mentioned the importance of authentic assessment in the nursing field as it provides learners with opportunities to practice real-world scenarios. Cagasan, et al. (2020) highlighted the significance of using alternative assessment methods in higher education that enable learners to locate their new knowledge in a wider social and realistic frame.

Educators also reported some limitations of authentic assessments, including being time consuming, difficult to create, and thus needing proper training to develop. These findings were confirmed by Reeves (2000) who noted that in higher education, educators rarely received adequate training in the use of assessment strategies and instructors were often confused in the process and procedures of design and reporting authentic assessment. Consequently, it is important that educators consider the advantages and disadvantages of each type to make an informed decision regarding which type of assessment to be used to evaluate students' skills and knowledge (Quansah, 2018).

The results of the study also revealed that there was no clear consensus regarding the preference of students for a specific assessment method. However, consensus was apparent in some areas: many students seemed to appreciate a greater 
degree of activities and situations that were associated with a learning goal. Wylie, E. C., \& Lyon, C. J. (2020) support this observation that many students preferred to apply what they knew to real-life scenarios and liked challenging questions. This observation was supported by Fook and Sidhu (2010). This may be due to the fact that many students have been heavily exposed to traditional assessments in general education, but in higher education (college level), they seemed to be more open to the possibilities of using newer methods of assessment, while others seemed more inclined towards more traditional techniques that could help in improving their academic achievement. When examining differences in students' attainments when using traditional and authentic assessments (Tables 8 and 9), the results showed that there was a statistically significant difference between students' grades in both types of assessment, where the students achieved higher grades in their exam that was of a traditional nature in comparison to their grades in the assignment, which had an authentic nature.

An interesting phenomenon appeared to emerge from the data. While some students preferred to apply their knowledge to real-life scenarios, a small percentage of students preferred questions that required scientific investigation, self-reflection, and opinion expression. This finding may raise the assumption that many students are not trained on how to use scientific inquiry to solve problems. This can help identify teaching and learning practices that need to be modified to help students acquire the skills of scientific thinking and inquiry.

Additionally, the results of the study revealed that many students preferred computerized assessment, which can be related to the shift to online learning amid COVID-19 crises. Students who are digital natives have an in-built understanding of digital technologies that have been integrated into their lives since early childhood, which will enable them to use the technology for their academic growth. This finding was confirmed by Özden (2005), who found that many students agreed on the effectiveness of the online assessment system, and the features of obtaining immediate scores and feedback increased their motivation and contributed positively to their attainment on the exam.

\section{Conclusion}

In light of the reform movement in education in the UAE and Jordan, dissonance arises over using tests as an indicator of learning. This study aimed to understand the effectiveness of using authentic and traditional assessments on students' performance in the field of health and educational sciences. Additionally, the study explored the preferences and attitudes of students and instructors the use of authentic and traditional types of assessments. The results showed that higher education institutions prefer both types of assessments and hence it is important that higher education institution attempt provide a bridge between authentic and traditional assessment.
Evaluation to the effectiveness of authentic and traditional assessments remains an important responsibility of educators. Educators must incorporate both traditional and authentic assessment procedures to accurately extrapolate growth. With the nationwide outcry for reform, combining the strengths of authentic and traditional assessment may help in educational progress of health and educational sciences students in higher education in each of the UAE and Jordan.

Hence, to welcome the move towards professionalizing the approach to supporting student learning within higher education in the UAE and Jordan, it is recommended that educators undertake some initial educational training to help them develop some appropriate skills and knowledge in relation to the complicated challenges in supporting student learning within the rapidly changing world of higher education. Moreover, it is important that educators provide a means of evidencing the achievement of learning outcome whether by adopting traditional or authentic assessment. This study is at the explorative stage but have provided some important evaluation and reflected the importance of diversifying assessments in supporting health and educational sciences students in higher education in each of the UAE and Jordan.

\section{Recommendations}

Both educators and students can benefit from this study, various outcomes of this study can lead educators to design a best model of assessment using both traditional and authentic assessment types. As for students, many advantages of using authentic assessment will help them enhance their academic writing and productivity skills. There is no clear boarder of using either traditional or authentic assessment as both types can be used in different ways and methods. The idea of mixing both types in assessing students work will lead to a great evaluation as recommended by this study.

\section{Ethical Considerations}

There were several ethical issues and concerns that required consideration before initiating the research and during the research study. These issues included ensuring that permissions were obtained from relevant authorities.

\section{Information and permission}

The data collected for this research included one public university in Abu Dhabi, United Arab Emirates (Fatima College of Health Sciences) and one university in Amman, Jordan (Amman Arab University). All students in the FCHS were female undergraduate students in the health science field. In all cases, appropriate permissions were sought from individuals and organizations. Prior to the administration of the questionnaires and interviews, clearance to conduct 
the study was first sought from the Human Research Ethics Committees in the two universities involved. An outline of the research, including its ethics approval, proposed dates for its start and completion, its aims and benefits, methodology, and details on how the results of the research would be disseminated, was provided. Subsequently, consent was also obtained from the participating students, and all students were told that completion of the questionnaire was entirely voluntary and that they could withdraw from the study at any time.

\section{Acknowledgments}

The authors thank Fatima College of Health Sciences in the United Arab Emirates and Amman Arab University in Jordan for allowing them to conduct the research on their premises.

\section{References}

Bailey, K., \& Brown, J. (1999). Learning about language assessment: Dilemmas, decisions, and directions \& new ways of classroom assessment. Learning, 4(2), 1-8.

Brawley, N. (2009). "Authentic Assessment versus Traditional Assessment: A Comparative study.” Ph.D. thesis, CCU Digital Commons is the institutional repository of Coastal Carolina University. Honors College and Center for Interdisciplinary Studies.

Cagasan, L., Care, E., Robertson, P., \& Luo, R. (2020). Developing a Formative Assessment Protocol to Examine Formative Assessment Practices in the Philippines. Educational Assessment, 1-17.

DeLuca, C., LaPointe-McEwan, D., \& Luhanga, U. (2016). Approaches to Classroom Assessment Inventory: A New Instrument to Support Teacher Assessment Literacy. Educational Assessment, 21(4), 248-266.

Dietel, R. J., J. L. Herman, and R. A. Knuth). 1991(. What does research say about assessment? NCREL, Oak Brook.

Dikli, S. (2003). "Assessment at a Distance: Traditional vs. Alternative Assessments." Turkish Online Journal of Educational Technology 2 (3): 13-19.

Fook, C.Y., and G. K. Sidhu. )2010(. "Authentic assessment and pedagogical strategies in higher education." Journal of Social Sciences 6 (2): 53-161.

Frey, B. B., \& Schmitt, V. L. (2007). Coming to terms with classroom assessment. Journal of Advanced Academics, 18(3), 402-423.

Ghosh, S., B. Brooks, D. Ranmuthugala, and M. Bowles.) 2020 (. "Authentic Versus Traditional Assessment: An Empirical Study Investigating the Difference in Seafarer Students' Academic Achievement." The Journal of Navigation 73 (4): 797-812. doi: https://doi.org/10.1017/S0373463319000894

Karim, A., A. Amir, M. Darman, Y. Muhammad. )2018( “"The Effectivity of Authentic Assessment Based Character Education Evaluation Model.” TEM Journal 7 (3): 495-500. doi:10.18421/TEM73-04

Koh, K. H. (2017). Authentic assessment. In Oxford research encyclopedia of education.

https://oxfordre.com/education/view/10.1093/acrefore/97801 90264093.001.0001/acrefore-9780190264093-e-22

Law, B., \& Eckes, M. (2007). Assessment and ESL: An alternative approach. Portage \& Main Press.
Mattison, K. M., Schroeder, H., Sculthorp, S. L., \& Zacharias, J. (2020). A return to doing: How authentic assessment changes higher education. In Learning and Performance Assessment: Concepts, Methodologies, Tools, and Applications (pp. 67-89). IGI Global.

McAfee, O., and D. Leong. )2007(. Assessing and guiding young children's development and learning. Boston: Pearson Education, Inc.

Meyer, A., and D. Rose. )2000(. "Universal design for individual differences." Educational Leadership 58 (3): 39-43.

Moria, E., R. Refnaldi, and M. Zaim. )2017(. "Using Authentic Assessment to Better Facilitate Teaching and Learning: The Case for Students' Writing Assessment." In Sixth International Conference on Languages and Arts (ICLA 2017). Atlantis Press.

Özden, M.Y. )2005(. “Students' perceptions of online assessment: A case study." International Journal of E-Learning \& Distance Education/Revue international du e-learning et la formation à distance 19 (2): 77-92.

Quansah, F. (2018). “Traditional or performance assessment: What is the right way in assessing learners." Research on Humanities and Social Sciences 8 (1): 21-4.

Reeves, T. C. )2000(. "Alternative assessment approaches for online learning environments in higher education." Journal of Educational Computing Research 23 (1): 101-111. doi: https:// doi.org/10.2190/GYMQ-78FA-WMTX-J06C

Simonson, M., S. Smaldino, M. Albright, and S. Zvacek. (2000). "Assessment for distance education." Chap. 11 in Teaching and Learning at a Distance: Foundations of Distance Education. Upper Saddle River, NJ: Prentice-Hall.

Weurlander, M., Söderberg, M., Scheja, M., Hult, H., \& Wernerson, A. (2012). Exploring formative assessment as a tool for learning: students' experiences of different methods of formative assessment. Assessment \& Evaluation in Higher Education, 37(6), 747-760.凶

Wiewiora, A., \& Kowalkiewicz, A. (2019). The role of authentic assessment in developing authentic leadership identity and competencies. Assessment \& Evaluation in Higher Education, 44(3), 415-430.

Wilsey, M., Kloser, M., Borko, H., \& Rafanelli, S. (2020). Middle School Science Teachersâ $€^{\text {Tx }}$ Conceptions of Assessment Practice Throughout a Year-long Professional Development Experience. Educational Assessment, 25(2), 136-158.

Winking, D.(1997). Critical issue: Ensuring equity with alternative assessments [online document]. NCREL (North Central Regional Educational Laboratory), Oak Brook: IL.

Wright, W. A., P. T. Knight, and N. Pomerleau. 1999. "Portfolio people: Teaching and learning dossiers and innovation in higher education." Innovative higher education 24 (2): 89-103.

Wylie, E. C., \& Lyon, C. J. (2020). Developing a Formative Assessment Protocol to Support Professional Growth. Educational Assessment, 1-17.

Wiewiora, A., \& Kowalkiewicz, A. (2019). The role of authentic assessment in developing authentic leadership identity and competencies. Assessment \& Evaluation in Higher Education, 44(3), 415-430.Wiewiora, A., \& Kowalkiewicz, A. (2019). The role of authentic assessment in developing authentic leadership identity and competencies. Assessment \& Evaluation in Higher Education, 44(3), 415-430.Bottom of Form 